\title{
AN EXPERIMENTAL INVESTIGATION OF POOL BOILING At Atmospheric Pressure
}

\author{
Md. Saimon Islam, Khadija Taslima Haque and Suman Chandra Saha \\ ${ }^{1}$ Department of Mechanical Engineering, BUET, Dhaka, Bangladesh
}

\begin{abstract}
This paper deals with an experimental investigation of pool boiling of water and methanol at atmospheric pressure from small horizontal heat sources. The heat sources are inserted into the copper tube submerged in a laterally-confined, finite pool of liquid. The saturated pool boiling heat transfer characteristics and the critical heat flux (CHF) condition were determined in the experiments. In the experiment, an attempt has been made to estimate the heat flux for pool boiling of Water and Methanol at atmospheric pressure. An indoor experiment was conducted to measure (i) the heat flux of water and methanol, (ii) the temperature of the working fluids, (iii) the wall superheat temperatures, (iv) the temperatures at the bottom and side of the pot, (v) time required to be superheated at definite time intervals for a given heat input. The heat input has been varied by changing the voltage with the help of a voltage regulator. A regression analysis has been performed by using the experimental data in the correlation of Rohsenow for pool boiling.
\end{abstract}

Keywords: Pool Boiling, Heat Flux, Wall Superhea and Correlation.

\section{Nomenclature}

$R \quad$ wire Radius [cm]

$I \quad$ electric current [A]

$V$ voltage [V]

$K$ thermal conductivity $[\mathrm{W} / \mathrm{m}-\mathrm{K}]$

$q$ generation heat flux $[\mathrm{kW} / \mathrm{m} 2]$

Te wall superheat $\left[{ }^{\circ} \mathrm{C}\right]$

$C_{p}$ specific heat $[\mathrm{J} / \mathrm{kg} / \mathrm{K}]$

$g$ gravitational acceleration $\left[\mathrm{m} / \mathrm{s}^{2}\right]$

$h_{f g}$ latent heat of evaporation $[\mathrm{J} / \mathrm{kg}]$

$T$ temperature $[\mathrm{K}]$

$\rho$ density $\left[\mathrm{kg} / \mathrm{m}^{3}\right]$

$\sigma$ surface tension $[\mathrm{N} / \mathrm{m}]$

$\mu \quad$ viscosity of the fluid $[\mathrm{Kg} / \mathrm{m} . \mathrm{s}]$

$T_{s} \quad$ surface temperature of the heater $\left[{ }^{\circ} \mathrm{C}\right]$

$T_{\text {sat }}$ saturation temperature of the fluid $\left[{ }^{\circ} \mathrm{C}\right]$

$T_{w}$ wall temperature $\left[{ }^{\circ} \mathrm{C}\right]$

$A$ cross sectional area of the test body $\left[\mathrm{m}^{2}\right]$

$x \quad$ distance $[\mathrm{m}]$

\section{Non-Dimensional Number \\ Pr Prandtl number}

$C_{s f}$ experimental Constant that depends on surface-fluid combination

$n$ experimental Constant that depends on the fluid

Subscript

$l \quad$ liquid phase

$v$ vapor phase

\section{Introduction}

When a surface immersed in a liquid is maintained at a temperature higher than the saturation temperature of the liquid, boiling may take place. The type of boiling depends upon the difference between these two temperatures. These are briefly described as follows. Natural convection boiling occurs at low temperature differences. The motion of the liquid is essentially due to natural convection. Nucleate boiling occurs at high temperature differences. Bubbles of vapour are formed at certain locations on the solid surface. These grow in size, detach from the solid surface, and rise to the liquid surface. Film boiling occurs at still higher temperature differences. The rate of evaporation becomes greater than that required to form bubbles. Hence, the bubbles coalesce and blanket the surface with a vapour film. This phenomenon begins at the peak heat flux. Dissipation of large heat fluxes at relatively small temperature differences is possible in systems utilizing boiling phenomenon as long as the heated wall remains wetted with the liquid. With the wetted wall condition at the heated surface, heat is transferred by a combination of two mechanisms: (i) bubbles are formed at the active nucleation cavities on the heated surface, and heat is transferred by the nucleate boiling mechanism, and (ii) heat is transferred from the wall to the liquid film by convection and goes into the bulk liquid or causes evaporation at the liquid-vapor interface. The large amount of energy associated with the latent heat transfer (compared to the sensible energy change in the liquid corresponding to the available temperature potential in the system) in the case of nucleate boiling, or the efficient heat 
transfer due to liquid convection at the wall, both lead to very high heat transfer coefficients. Removal or depletion of liquid from the heated wall therefore leads to a sudden degradation in the heat transfer rate.

Critical Heat Flux condition represents the upper limit of heat flux (in heat flux controlled systems) followed by a drastic rise in wall temperature, or considerable degradation in heat flux with an increase in wall temperature (in temperature controlled systems) in the nucleate boiling heat transfer. A vapor blanket covers the heated surface separating the surface from the liquid.

\section{Previous Work}

\section{Historical Perspective}

A relatively recent paper by Groeneveld et al. (1996) developed jointly by AECL Research (Canada) and IPEE (Obninsk, Russia). It is based on an extensive database of $\mathrm{CHF}$ values in tubes with vertical upflow of steam-water mixtures.

A comprehensive paper by Nariai and Inasaka (1992) presents a summary of their own experimental work and presents useful parametric relationships between $C H F$ and important system variables. A comparison with the available correlations is also presented. A recent review of $\mathrm{CHF}$ fundamentals, models and correlation schemes is presented by Celata and Mariani (1999). They present a comprehensive summary of investigations of the $C H F$ condition and reflect our current understanding of this phenomenon. Earlier review articles by Celata $(1992,1997)$ provide a good overview of the models describing the CHF mechanism.

Tong and Tang (1997) present a very comprehensive summary of the available literature on various aspects of boiling crisis. A large number of correlations have been compiled and presented from the available literature. In view of the excellent recent surveys already available in literature, the focus of the present paper is directed toward gaining a fundamental understanding through the theoretical models and experimental observations. Areas for future research are identified to gain further insight into the mechanisms leading to $\mathrm{CHF}$.

\section{Application Areas for CHF Studies}

The historical applications such as quenching are still valid. The major impetus for the $C H F$ studies in the recent past was the nuclear reactor core cooling. The catastrophic nature of the disaster associated with the CHF in a nuclear reactor, leading to core meltdown, put a high premium on the $C H F$ studies. The urgency of the problem led to exhaustive experimentation in geometries similar to the reactor core. The safe operating limits were established through compilation of data from various experiments. In exhaustive literature survey report, Boyd (1983a, b) points out the severe inadequacies in the theoretical modeling of the $C H F$ phenomena leading to empiricism. However, the emphasis has now moved toward gaining the basic understanding of the mechanisms leading to the $C H F$ condition. Developments in new augmentation techniques have opened a whole new area where extensive CHF data for specific systems are not available.

\section{Experimental Setup and Procedure}

To conduct experiments, an experimental set up as shown in Fig. 1 is used. It includes a Beeker, One Copper thin cylindrical rod, Cartridge heater and measuring instruments, electric power supply system. The Beeker capacity was $2000 \mathrm{ml}$. The experiment has been conducted at atmospheric pressure. The glass beeker has been used to observe bubble dynamics on the tube. The heating tube is shown schematically in Fig. 2. It is a copper cylinder having the dimensions given. One end of it is closed (undrilled portion) of $1.35 \mathrm{~cm}$ thickness whereas the other end is open. The small thickness reduces the losses of heat flow longitudinally. Insulating materials (heat resisting glue) after insertion of the heater in the tube fills open end of the tube.

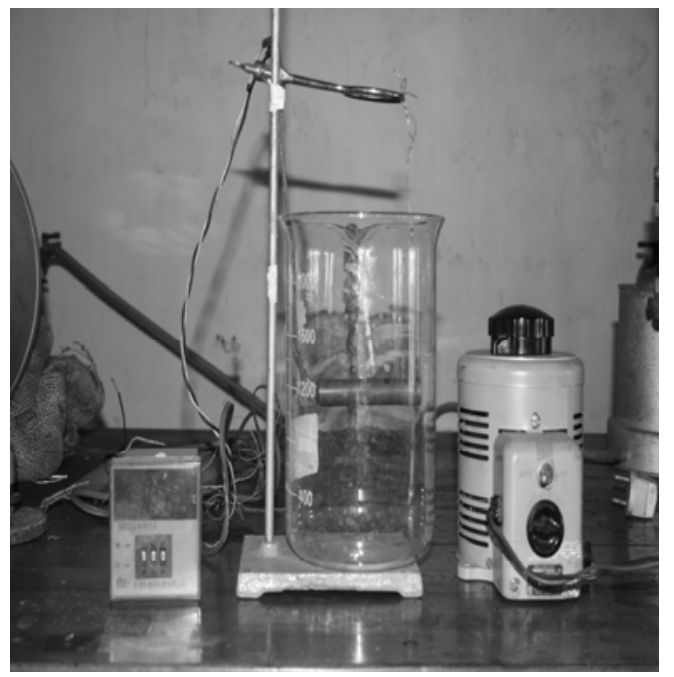


Fig. 1: Experimental set up

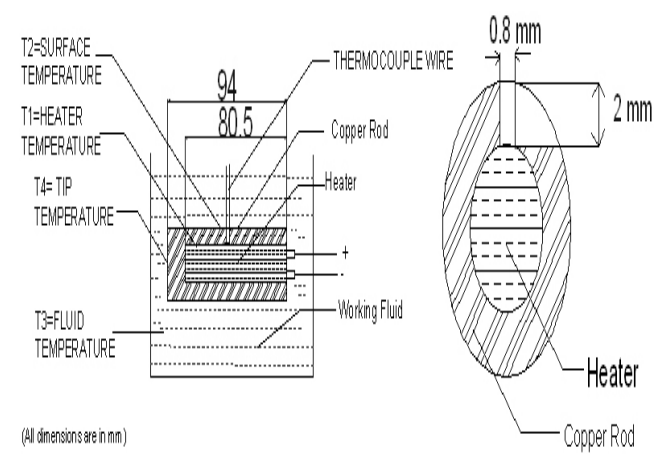

Fig. 2: Schematic diagram of the experimental facility

The Cartridge heater is installed inside the tube having length of $8.05 \mathrm{~cm}$ and radius of 0.477 $\mathrm{cm}$. Cartridge heater length has been considered as actual effective heat transfer length. Calibrated K- Type thermocouples are used to measure surface and liquid temperatures. The thermocouple is placed inside a hole of $3 \mathrm{~mm}$ depth made in the wall of Copper rod to measure the inside temperature of the copper rod indicating the heater temperature. Similarly, probes are placed in the liquid pool corresponding to top, bottom, and the two side-positions of the heating tube for the measurement of liquid temperature. The probes are placed in the liquid pool at sufficient distance from the heating tube to ensure that they are outside the superheated boundary layer surrounding the tube.

The cartridge heater was drilled inside a cylindrical copper rod to heat the copper rod surface. Wire was placed inside the small drilling hole with the help of a heat resistance glue. The copper rod was immersed horizontally inside a beaker of working fluid and was supported with the help of stand and clamp.

The working fluids used in this experiment are Water $\left(\mathrm{H}_{2} \mathrm{O}\right)$ and Methanol $\left(\mathrm{CH}_{3} \mathrm{OH}\right)$. Fluid is heated up by the test surface(copper) which is submerged in the liquid, boils and evaporate.

Heating tube are laid horizontally in the biker in such a manner that their closed ends remain floating in liquid pool. Distilled water is filled in the Beeker up to the height of $2000 \mathrm{ml}$. A variac modulates input voltage to the heater. At steady state condition readings of all thermocouples, ammeter and variac are noted. Heat input to heater is increased progressively in several steps and experiments are repeated significantly .

The average outside-wall temperature of tube was calculated by the one-dimensional cylindrical heat conduction equation according to the average value of the temperatures of thermocouples measured on the tubes and the distance between the tube surface and the centers of the thermocouples. The heat fluxes were calculated by dividing the measured electric powers (after correcting for the small losses from the two ends of the tube) by the tube surface area based on the diameter and the effective heated length.

The relative system measurement errors of the superheat, were less than $\pm 3 \%$. During this investigation the maximum uncertainty of the heat fluxes is less than $7 \%$ which is caused by both errors of the heated area and due to a sufficiently long $\mathrm{L} / \mathrm{D}$ ratio and relatively low superheat, the heat losses from the two ends of the test tube have little influence on the temperature field of the surface of the copper tube.

\section{Experimental Results and Discussion 4.1 Influencing Parameters}

The most important parameters of influence on pool boiling heat transfer of fluids are heat flux $\mathrm{q}$, saturation pressure $\mathrm{p}_{\mathrm{s}}$ and properties of the boiling fluid. Additional influences result from material and micro structure (surface roughness) or macro structure (shape) of the heating elements, from their arrangement (inclination to gravity; geometry), and from operating conditions of the evaporators (impurities of the fluid).

The pool boiling heat transfer relations can apply to smooth surfaces.

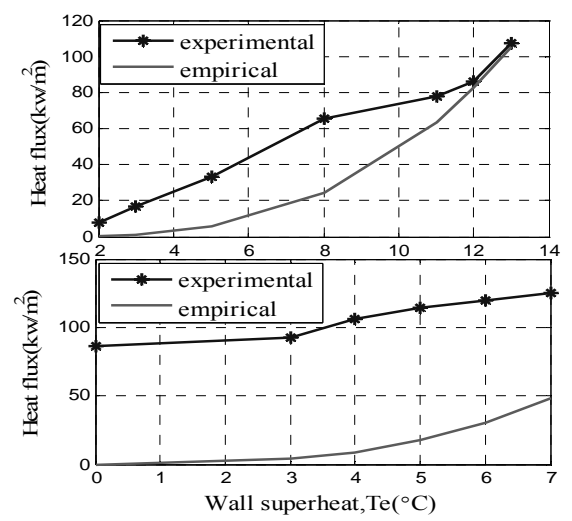

Fig. 3: Comparison between experimental and empirical heat flux of Methanol and Water in pool boiling at atmospheric pressure. 
As the rate of heat transfer in the nucleate boiling regime strongly depends on the number of active nucleation sites on the surface and the rate of bubble formation at each site. It is observed that irregularities on the heating surface, including roughness and dirt, serve as additional nucleation sites during boiling. The first bubbles are likely to form at the scratches on the heating surface. These scratches act like nests for the bubbles to form and thus increase the rate of bubble formation. Such surfaces are reported to enhance heat transfer in the nucleate boiling regime (Fig. 3).

From the above figures the high heat transfer rates cannot be sustained for long since the effect of surface roughness is observed to decay with time and the heat flux to drop eventually to near the values encountered on smooth surfaces.

At small differences between the boiling surface and the saturation temperature, up to $\Delta \mathrm{T} \sim 2-3 \mathrm{~K}$, the heat fluxes are gradually increased. From $\Delta T \sim 3 K$, the heat flux starts to deviate by a sharp increase of heat flux. At wall superheat of $3-7 \mathrm{~K}$ the heat flux is higher than at larger scale.

\subsection{Effects of Working Fluid \\ 4.2.1 Considering Boiling Curve}

With the same heating area, the boiling curve for water it has been observed that the enhancement of heat flux is much higher than that of methanol. Since surface tension of Methanol is smaller than that of Water and latent heat of evaporation was even smaller, when methanol was used as working liquid, the microlayer at the bottom of coalesced bubbles was more liable to be dried out. Heat transfer deterioration appeared in part of the area, and the global effect of heat transfer enhancement was poorer than that of water (Fig. 4).

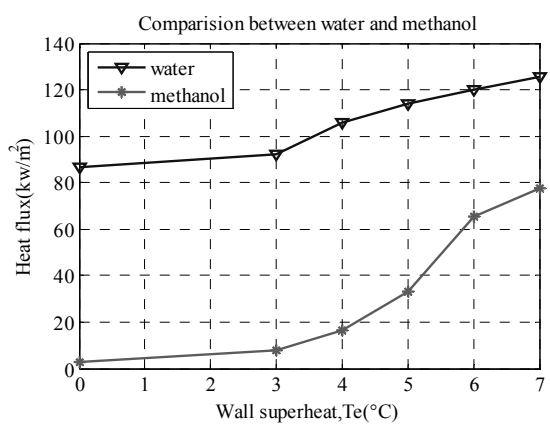

Fig. 4: Variation of heat flux of methanol and water with wall superheat(experimentally) in pool boiling at atmospheric pressure
Through experiments it has been observed that the size of the bubble in case of Methanol increases due to its greater volume expansion co-efficient than that of water. With increase in bubble size, frequency of bubble formation decreases which results in reduced heat transfer.

\subsubsection{Considering Conductivity and Moleculer Mass}

From the collected data and observing the plot of boiling curve for both liquids in the convection region the slope is steeper for water than that of methanol which must be the reason of larger heat conductivity of water than that of methanol due to the higher moleculer mass of methanol as conductivity decreases with increasing molecular mass.

\subsubsection{Considering Superheat Condition}

The wall temperature of the methanol system was the lowest and provided steady boiling behavior and reduced the fluctuations in wall temperature from that of distilled water.

\subsection{Variation of Heat Flux with Time}

Since bubble growth depends on a sufficient superheating of the surrounding liquid, fluid properties, and available superheat. Bubble growth is expected to take place from an active cavity (cavity with residual gasses or vapor) when the surrounding liquid reaches the required superheat. An appreciable time may be required to reheat the liquid in the vicinity of the wall to a superheated state and initiate subsequent bubble growth.

Time required for the surface of heater to be superheated in definite heat input here referred as Time of Superheat. Time to be superheated is largely depends on the rate of bubble growth and departure as they act as energy mover.The stirring and agitation caused by the entrainment of the liquid to the heater surface is primarily responsible for the increased heat flux.The length of time from the beginning of bubble growth to bubble departure, depends on how large the bubble must become for release to occur. This interval therefore depends on the rate at which the bubble grows to departure size. The departure bubble size is determined from the net effect of forces acting on the bubble as it grows on the surface. Surface tension holds the bubble down. 


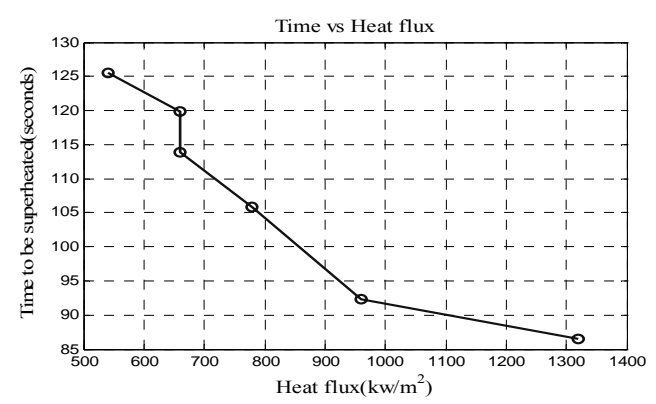

Fig. 5: Variation of heat flux of water with time in pool boiling at atmospheric pressure.

For an upward-facing horizontal surface, buoyancy pulls the bubble up. If the bubble grows rapidly, the inertia associated with the induced liquid flow around the bubble may also tend to pull the bubble away. Bulk liquid motions may also produce lift forces on the bubble causing it to be pulled away (Fig. 5).

At higher heat flux levels time of super heat decreases, and the number of active nucleation sites and the frequency of bubble departure increases. As the flux increases, the boiling becomes more continuous.

\subsection{Variation of Heat Transfer Co-efficient with Heat Input}

The variation in convective heat transfer coefficient for the different values of heat input has been shown in Fig. 6. It is observed that it is strongly dependent on the heat input, as expected. It varies from 18 to $30 \mathrm{~kW} / \mathrm{m}^{2}{ }^{\circ} \mathrm{C}$ for the heat input range from 230 to $318 \mathrm{~W}$. These results are in accordance with those reported in the literature.

The increasing trend in the values of $h$ with the increase in the heat input may be due to a higher surface temperature and the rapid formation of vapour bubbles at the surfaceliquid interface. It is further noted that the heat transfer rate is increasing with $\left(T_{s}-T_{s a t}\right)$ at low values of heat input.

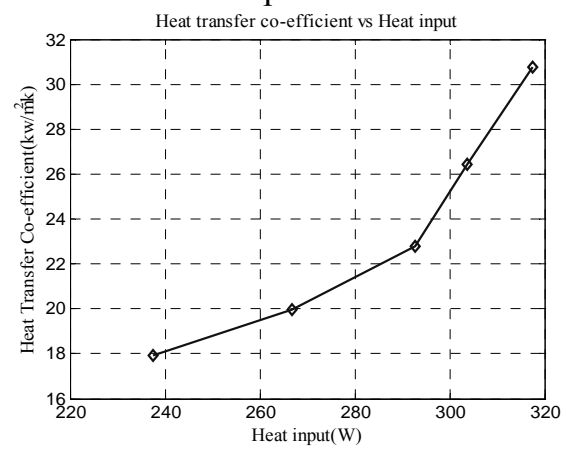

Fig. 6: Variation of heat transfer co-efficient with heat input in pool boiling of water at atmospheric pressure.

\subsection{Regression Analysis for Experimental constants}

Rohsenow Correlation is,

$$
\mathrm{q}^{\prime \prime}=\mu_{1} \mathrm{~h}_{\mathrm{fg}}\left[\mathrm{g}\left(\rho_{1}-\rho_{\mathrm{v}}\right) / \sigma\right]^{1 / 2}\left[\mathrm{C}_{\mathrm{pl}}\left(\mathrm{T}_{\mathrm{s}}-\mathrm{T}_{\mathrm{sat}}\right) / \mathrm{C}_{\mathrm{sf}}\right.
$$
$\left.\mathrm{h}_{\mathrm{fg}} \operatorname{Pr}_{1}^{\mathrm{n}}\right]^{3}$

This eq.can be written in the form

$$
\mathrm{C}_{\mathrm{sf}} \mathrm{Pr}_{1}^{\mathrm{n}}=\mathrm{R}
$$

Taking the logarithm of both sides of the above equation, one can write

$$
\begin{aligned}
\log R & =\log \left(C_{s f} P_{1}^{n}\right) \\
\log R & =\log C_{s f}+n \log P_{1} \\
& =\log C_{s f}+n \log \left(\mu_{1} C_{p l} / K\right)
\end{aligned}
$$

The above equation represents the straight line in the following form

$$
\begin{aligned}
& \mathrm{y}=\mathrm{a}_{\mathrm{o}}+\mathrm{nx} ; \\
& \text { Where } \mathrm{y}=\log \mathrm{R} \\
& \mathrm{a}_{\mathrm{o}}=\log \mathrm{C}_{\mathrm{sf}} \\
& \mathrm{x}=\log \left(\mu_{1} C_{\mathrm{pl}} / \mathrm{K}\right)
\end{aligned}
$$

$R$ in the above expression is calculated for the various temperatures $\left(T_{s}-T_{\text {sat }}\right)$ recorded during the experiments on pool boiling using the physical properties of liquids. The corresponding values of $\mathrm{x}$ and $y$ are also computed. Thus, the values of $n$ and ao in are obtained by using the following expression obtained by the least square linear regression method.

$\left.\left(\sum \mathrm{x}_{\mathrm{i}}\right)^{2}\right)$

$$
\mathrm{n}=\left(\mathrm{N} \sum \mathrm{x}_{\mathrm{i}} \mathrm{y}_{\mathrm{i}}-\sum \mathrm{x}_{\mathrm{i}} \sum \mathrm{y}_{\mathrm{i}}\right) /\left(\mathrm{N} \sum \mathrm{x}_{\mathrm{i}}^{2}-\right.
$$

$$
\begin{aligned}
& \mathrm{a}_{0}=\left(\sum \mathrm{y}_{\mathrm{i}} / \mathrm{N}\right)-\mathrm{n}\left(\sum \mathrm{x}_{\mathrm{i}} / \mathrm{N}\right) \\
& \mathrm{C}_{\mathrm{sf}}=\mathrm{e}^{\mathrm{ao}}
\end{aligned}
$$

where $N$ is the number of observations in each set of heat input.

\subsection{Heat flux vs superheat wall at different heat input}

Fig. 4.6 shows that the variation of heat transfer rate with (Ts - Tsat) for different values of heat input. This figure indicates that $q$ rises exponentially with (Ts - Tsat) as well as heat input, as expected, due to fast mass evaporation from the water in the beginning.

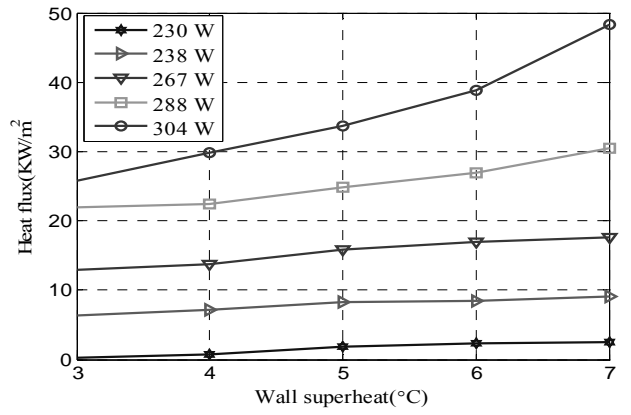

Fig. 7: Variation of heat flux with wall superheat at different heat input in pool boiling of water at atmospheric pressure. 
From the figure 4.6 incresing the heat input the heat flux increases and at higher input heat flux rapidly increased showing the steeper curve (Fig. 7).

\subsection{Variation of Wall Temperature along the Circumference}

Fig. 8 is a plot to demonstrate the variation of wall temperature along the circumference of heating tube for the boiling of distilled water at atmospheric pressure. The behaviour of this plot can be explained as follows. Initiation of vapour bubble occurs at the preferred sites randomly distributed on the surface of the heating tube. The vapour bubbles grow in size and depart from the heating surface after attaining their maximum size. However, geometry of the heating tube causes hindrance in the free movement of the vapour bubble at some of the circumferential positions. In fact, bubble at the top-most position has free access for its movement, whereas those at the bottommost position do not have so. Therefore, bubbles at the top-most position have the highest emission frequency, whereas those at the bottom-most position have the least, and those at the side positions have in between the two. Hence, wall temperature is found to increase continuously from top to side to bottom positions of the heating tube.

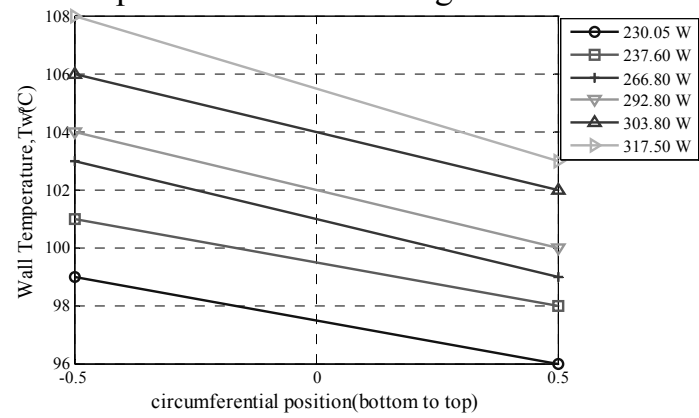

Fig. 8: Variation of wall temperature along the circumference for the pool boiling of distilled water at atmospheric pressure.

At a given circumferential position, increase in wall temperature due to increase in heat flux is quite obvious as it leads to higher values of wall superheat required for higher heat transfer rate.

\section{Conclusions}

An experimental observation has been established for pool boiling of water and methanol from a copper tube with horizontal orientation. In addition, the results were compared with empirical correlations. The following conclusions can be reported.

1. Heat transfer coefficients and critical heat flux are strongly dependent on the fluid properties. Fluids with a low surface tension, such as alcohols, will wet a given surface better and have a lower contact angle than higher surface tension fluids such as water.

2. At higher heat flux levels time of super heat decreases, and the number of active nucleation sites and the frequency of bubble departure increases. As the flux increases, the heat flux in boiling becomes less fluctuating.

3. Pool boiling experiments has been performed on two types of liquids. Experimental data agreed well with Rohsenow correlation.

4. In pool boiling from a cylinder the wall superheat is established in the bottom surface earlier than top surface.

5. The boiling curve is for water and methanol exhibited the similar trends comparing to the Nukiyama boiling curve.

\section{References}

[1] S. Nukiyama, Maximum and minimum values of heat $\mathrm{q}$ transmitted from metal to boiling water under atmospheric pressure. J. Soc. Mech. Eng. Jpn. 37 (1934) 53-54, 367-374.

[2] G.N. Tiwari, Om Prakash, Subodh Kumar .Evaluation of convective heat and mass transfer for pool boiling of sugarcane juice. Centre for Energy Studies, Indian Institute of Technology, Hauz Khas, New Delhi 110 016, India, 2 June 2003.

[3] Dr S Kumar, Dr B Mohanty, Dr S C Gupta.Boiling Heat Transfer Co-efficient from a Vertical Row of Horizontal Tubes. Mechanical Engineering Department, National Institute of Technology, Jamshedpur 831 014; December 31, 2003.

[4] Critical Heat Flux in Subcooled Flow Boiling - an Assessment of Current Understanding And Future Directions for Research. S. G. Kandlikar Mechanical Engineering Department, Rochester Institute of Technology, Rochester, NY 14623, USA

[5] ASME. Test Uncertainty. PTC 19.1-1998. American Society of Mechanical Engineers, New York, 1998.

[6] S.J. KIM, I.C. BANG, J. BUONGIORNO and L.W. HU. Study of pool boiling and critical heat flux enhancement in nanofluids. Massachusetts Institute of Technology, 77 Massachusetts Avenue, Cambridge, 02139-4307 MA, USA

[7] Dhir VK. Results of some recent studies on pool nucleate and film boiling. In: Proceeding of the Fifth ISHMTASME $\mathrm{H}$ and MT Conference and Sixteenth National H and MT Conference 2002, 3-5 January. 
[8] Farber EA, Scorah EL. Heat transfer to water boiling under pressure. Trans ASME 1948;70:369-84.

[9] Husain S, Mohanty B, Gupta SC, (Late) Varshney BS. Energy conservation through enhanced heat transfer coefficient. In: Proceeding of the Fifth ISHMT-ASME H and MT Conference and Sixteenth National H and MT Conference 2002, 3-5 January.

[10] Labuntsov DA. Heat transfer problems with nucleate boiling of liquids. Therm Eng 1972:21-8.

[11] Pioro IL. Experimental evaluation of constants for the Rohsenow pool boiling correlation. Int J Heat Mass Transfer 1999;42:2003-13.
[12] Rohsenow WM. A method of correlating heat transfer data for surface boiling of liquid. Trans ASME 1952;74:969-76.

[13] Young RK, Hammel RL. Higher coefficients for heat transfer with nucleate boiling. Chem Eng Prog Symp Ser 1965;61(59):264-70.

[14] S. Moghaddam, K.T. Kiger, Pool Boiling Mechanism of HFE-7100, ASME Heat Transfer/Fluids Engineering Summer Conference, July 11-15, 2004.

[15] Cengel YA. Heat transfer-a practical approach. USA: McGraw-Hill Companies; 1998. 